\title{
PENGARUH PENDIDIKAN DAN PELATIHAN TERHADAP KINERJA PENGURUS PGRI KABUPATEN PARIGI MOUTONG DAN GUNUNG KIDUL
}

\author{
Rahmatiah \\ Program Studi Informatika, Universitas Indraprasta PGRI \\ Email: rahmatiahrasidin@gmail.com
}

\begin{abstract}
Abstrak
Penelitian ini bertujuan untuk mendeskripsikan pengaruh pendidikan dan pelatihan terhadap kinerja pengurus PGRI di Kabupaten Parigi Moutong dan Kabupaten Gunung Kidul. Pertanyaan penelitian adalah bagaimana pengaruh pendidikan dan pelatihan terhadap kinerja pengurus PGRI di Kabupaten Parigi Moutong dan Kabupaten Gunung Kidul? Data dari penelitian ini adalah dalam bentuk laporan tengah semester dan akhir semester tentang perkembangan 5 aspek penguatan organisasi setelah dilakukan pelatihan serta data dari Sistem Informasi Keanggotaan dan Sistem Informasi Keuangan PGRI. Data dianalisis dengan data dalam bentuk tabel menggunakan metode dekriptif-kualitatif. Berdasarkan analisis data, hasil kinerja pengurus PGRI di kedua kabupaten tersebut meningkat ditandai dengan meningkatnya 5 aspek penguatan organisasi setelah dilakukan pendidikan dan pelatihan. Hasil lain adalah pengurus PGRI di tingkat cabang di kabupaten ikut termotivasi untuk memajukan organisasi.
\end{abstract}

Kata Kunci: pendidikan dan pelatihan, kinerja, pengurus PGRI, penguatan organisasi.

\begin{abstract}
This study aimed to describe the effect of education and training on the performance of PGRI Board in Parigi Moutong and Gunung Kidul districts. The research question is how the influence of education and training on the performance of PGRI Board in Parigi Moutong and Gunung Kidul Districts? Data from this research are the mid-term report and end semester report form the districts about the progress of 5 aspects of organizational strengthening after training and also the data from PGRI's Membership Information System and Financial Information System. Data were analyzed with data in table form using descriptive-qualitative method. Based on the data analysis, PGRI board performance in both districts increased marked by the increase of 5 aspects of organizational strengthening after education and training. Another result is the PGRI board at the branch level in the two districts are motivated to improve organization.
\end{abstract}

Keywords: education and training, performance, PGRI Board, organizational strenthening.

\section{PENDAHULUAN}

Sumber daya manusia (SDM) merupakan faktor yang sangat penting dalam sebuah organisasi. SDM adalah elemen utama organisasi dibandingkan dengan elemen lain, karena manusia yang mengendalikan yang lain. Tanpa adanya SDM maka perusahaan tidak bisa dijalankan. Untuk membangun suatu perusahaan yang sehat dan unggul diperlukan SDM yang berkualitas dan mumpuni di bidangnya. Pengelolaan dan pengembangan sumber daya manusia merupakan suatu investasi bagi organisasi karena diperlukan biaya untuk mendukung hal tersebut, namun sejalan dengan hal tersebut, manfaat yang didapat oleh organisasi juga besar karena pengurus dan/atau pegawai yang dimiliki menjadi profesional dan handal dalam mengerjakan segala pekerjaan di organisasi tersebut.

Tantangan yang dihadapi organisasi seperti perubahan lingkungan organisasi, lingkungan kerja, teknologi, menghendaki organisasi harus melakukan perubahan dan pengembangan SDMnya secara proaktif, sehingga tidak terjadi keusangan kemampuan SDM untuk memajukan organisasi. Prof. Dr. H. Edy Sutrisno, M. 
$\mathrm{Si}$ berpendapat bahwa dalam rangka persaingan ini organisasi/perusahaan harus memiliki sumber daya yang tangguh. Betapapun majunya teknologi perkembangan informasi, tersedianya bahan, jika tanpa SDM sulit bagi organisasi itu untuk mencapai tujuannya.[1]

Pendidikan dan pelatihan (diklat) merupakan salah satu cara organisasi untuk menghadapi berbagai tantangan tersebut dengan tujuan untuk meningkatkan dan mengembangkan kemampuan intelektual dan kepribadian SDM yang ada dalam struktur organisasi. Hal ini didasari atas upaya organisasi untuk dapat mencapai visi, misi, dan tujuan organisasi seperti tentang definisi pelatihan sebagai berikut: [2] "Training is a process used by organizations to meet their goals. It is called into operation when discrepancy is perceived between the current situation and preferres state of affairs. The trainers role is to facilitate trainee's movement from the status quo toward the ideal"

Dari pendapat di atas disimpulkan bahwa melalui pelatihan dapat mengatasi kesenjangan saat ini dengan situasi yang diinginkan di masa depan. Hal ini dikuatkan oleh Faustino Cardoso Gomes dalam Andri Irawan yang berpendapat bahwa pelathan sering dipakai sebagai solusi atas persoaan kinerja organisasi.[3]

Persatuan Guru Republik Indonesia (PGRI) merupakan organisasi profesi guru telah tumbuh menjadi organisasi yang besar dengan rentang kendali yang amat panjang. Struktur organisasinya meliputi seluruh wilayah tanah air Indonesia, mulai dari tingkat nasional di Pengurus Besar PGRI, tingkat provinsi, tingkat kabupaten/kota sampai dengan satuan pendidikan di tiap wilayah. Namun demikian, belum sepenuhnya tumbuh sebagai organisasi yang kuat, independen, demokratik, dan sustanable.
Kondisi PGRI di berbagai daerah sangat variatif terutama di tingkat kabupaten/kota. Ada yang telah tumbuh kuat, ada yang masih dalam tahap berkembang dan ada yang masih memerlukan pembinaan khusus. Begitu juga dengan kondisi pengurusnya. Dalam berbagai forum organisasi muncul dinamika dan situasi yang menunjukkan bahwa belum semua pengurus memahami secara persis tentang aturan- aturan organisasi yang standar, pengelolaan organisasi secara baik, dan bagaimana menjadi organisasi yang responsive terhadap perubahan.

Berdasarkan latar belakang dapat ditentukan masalah dalam penelitian ini yaitu "Bagaimana cara organisasi meningkatkan kemampuan pengurusnya? Apakah pendidikan dan pelatihan dapat meningkatkan kemampuan pengurus? Bagaimana pengaruh pendidikan dan pelatihan terhadap kinerja pengurus PGRI?

Secara umum, penelitian ini bertujuan untuk mendeskripsikan pengaruh pendidikan dan pelatihan terhadap kinerja pengurus PGRI di tingkat kabupaten/kota. Melalui penelitian ini diharapkan dapat diperoleh manfaat secara teoretis maupun praktis. Secara teoretis, hasil penelitian ini diharapkan bermanfaat bagi pengembangan ilmu bidang pengembangan Sumber Daya Manusia, khususnya pengaruh pendidikan dan pelatihan pada pengembangan SDM. Secara praktis, diharapkan penelitian ini dapat bermanfaat bagi pihak-pihak yang terkait yaitu para pemangku kepentingan organisasi, pengurus, dan karyawan.

Pendidikan dan Pelatihan

1. Konsep Dasar Pendidikan dan Pelatihan Notoatmodjo dalam Dharta I. Ketut berpendapat bahwa secara konseptual membedakan antara pendidikan dan pelatihan. Pendidikan pada umumnya 
berkaitan dengan mempersiapkan calon tenaga yang diperlukan oleh suatu instansi atau organisasi, sedangkan pelatihan (training) lebih berkaitan dengan peningkatan kemampuan atau ketrampilan karyawan yang sudah menduduki suatu pekerjaan atau tugas tertentu. [4]

Dalam pendidikan, orientasi atau penekanannya pada pengembangan kemampuan umum, sedang pada pelatihan lebih pada tugas yang harus dilaksanakan. Pendidikan dianggap lebih luas lingkupnya dibanding pelatihan. Dengan kata lain, pelatihan menekankan kepada kemampuan psikomotor, meskipun didasari pengetahuan dan sikap, sedangkan dalam pendidikan ketiga area kemampuan tersebut (pengetahuan, sikap dan ketrampilan/psikomotor) memperoleh penekanan yang merata. Karena orientasi atau penekanannya pada pelaksanaan tugas serta kemampuan khusus pada sasaran, maka jangka waktu pelatihan pada umumnya lebih pendek daripada pendidikan.

Sedangkan menurut Peraturan Pemerintah Nomor 31 Tahun 2016 tentang Sistem Pelatihan Kerja Nasional menyatakan bahwa pelatihan kerja adalah keseluruhan kegiatan untuk memberi, memperoleh, meningkatkan, serta mengembangkan kompetensi kerja produktivitas, displin sikap, dan etos kerja pada tingkat keterampilan dan keahlian tertentu sesuai dengan jenjang dan kualifikasi jabatan atau pekerjaan. [5]. Pelaksanaan pendidikan dan pelatihan haruslah direncanakan dan diorganisasikan untuk mendapatan efektifitas dalam pelaksanaannya [6]

Berdasarkan terminologi diatas, dapat disimpulkan bahwa konsep "pendidikan" dan "pelatihan" tidak dapat dipisahpisahkan dan ini merupakan satu kesatuan. Implementasinya, dalam suatu institusi atau organisasi khususnya di kalangan birokrasi pendidikan pelatihan biasanya disatukan menjadi "diklat". Diklat harus direncanakan dengan baik dengan tujuan meningkatkan kinerja pegawai/karyawan/pengurus untuk mencapai visi, misi, dan tujuan suatu perusahaan/organisasi.

\section{Program Pendidikan dan Pelatihan}

Menurut Michael R. Carrel dalam jurnal Syamsul Maarif, et.al pelatihan dibagi menjadi menjadi dua, yaitu [7]:

a. Program pelatihan umum

Pelatihan umum merupakan pelatihan yang mendorong karyawan untuk memperoleh keterampilan yang dapat dipakai dihampir semua jenis pekerjaan. Pendidikan karyawan meliputi keahlian dasar yang biasanya merupakan syarat kualifikasi pemenuhan pelatihan umum. Misalnya, cara belajar untuk memperbaiki kemampuan menulis dan membaca serta memimpin rapat akan bermanfaat bagi setiap pengusaha, siapapun yang secara individu dapat mengerjakannya.

b. Pelatihan khusus

Pelatihan khusus adalah pelatihan di mana para karyawan memperoleh informasi dan keterampilan yang sudah siap pakai, khususnya pada bidang pekerjaannya. Pelatihan khusus, misalnya mengusahakan agar sistem anggaran perusahaan khususnya dapat berjalan. Karena tiap perusahaan memiliki sistem anggaran tersendiri, pelatihan ini secara langsung bermanfaat hanya bagi karyawan yang sudah ada.

\section{Tujuan Program Latihan dan Pengembangan}

Tujuan program latihan dan pengembangan dalam suatu organisasi adalah menutup "gap" antara kecakapan atau kemampuan karyawan dengan permintaan jabatan dan meningkatkan efisiensi dan aktivitas kerja karyawan dalam mencapai sasaran kerja yang ditetapkan. Tujuan penyelenggaraan 
program pelatihan yaitu untuk memperbaiki kemampuan seseorang dalam kaitannya meningkatkan pengetahuna, keterampilan, kecakapan serta sikap seseorangyang diperlukan organiasi dalam mencapai tujuan. [8]

\section{Prinsip-prinsip dan Sistem Pendidikan dan Pelatihan}

Pendidikan dan pelatihan saat ini merupakan suatu keharusan dilakukan oleh suatu organisasi dan tidak dapat diabaikan karena hal ini dapat dipandang sebagai penanaman modal (investasi). Oleh karena itu, sangat masuk akal apabila pendidikan dan pelatihan harus diperhatikan secara serius dengan memerhatikan prinsipprinsip berikut [9]:

a. Diklat sebagai Penyempurnaan

Keluaran pendidikan normal pada umumnya masih dalam keadaan siap latih. Terlebih lagi karena pendidikan di Indonesia masih bersifat masal karena sangat mengutamakan pemerataan. Mereka belum siap dan mampu untuk memegang jabatan tertentu. Oleh karena itu, sumber daya manusia ini masih harus disempurnakan dalam satu diklat terprogram.

b. Diklat sebagai Pelayanan Kemajuan IPTEK

Perkembangan IPTEK tidak dapat dihindari lagi sehingga apa yang dipelajari di bangku sekoilah tahun ini mungkin telah berubah dan diperbaiki.

c. Diklat sebagai Wahana Promosi

Organisasi selalu ditingkatkan mutu pelayanannya pada setiap tingkatan jabatan yang ada dalam organisasi itu. Semakin tinggi jabatan, semakin dibutuhkan orang yang berkualitas. Peningkatan kualitas karyawan pada umumnya diperoleh melalui pendidikan dan latihan yang direncanakan secara sistematis.

\section{d. Diklat sebagai pengembang Keterampilan}

Tugas-tugas dalam Lembaga atau organisasi sering memerlukan keterampilan khusus. Oleh karena itu, karyawan yang akan menangani tga itu harus mendapatkan pendidikan dan pelatihan khusus. Tanpa pembinaan dan pengembangan keterampilan ini, produktivitas karyawan akan menurun.

e. Diklat sebagai Pembentukan Etos Kerja Bermutu

Kecenderungan dan semangat kerja karyawan melakukan tugas tidak timbul dengan sendirinya, tetapi perlu dipupuk dan disempurnakan melalui berbagai kegiatan penyegaran yang direncanakan secara matang dalam penyegaran secara matang. Dalam penyelenggaraan dan pelatihan yang dikoordinasi dengan baik, etos kerja karyawan dapat meningkat.

\section{Pelatihan Pengurus PGRI Tingkat Kabupaten/Kota}

PGRI organisasi nirlaba (non profit) yang dalam rangka meningkatkan kinerja pengurusnya PGRI di berbagai tingkatan memerlukan strategi seperti melakukan kerja sama. Pengurus Besar PGRI menjalin kerja sama dengan berbagai pihak baik dalam maupun luar negeri. Di dalam negeri, PGRI telah bekerja sama dengan berbagai pihak seperti MPR/DPR/DPD RI, berbagai kementerian terkait, PT. Telkom, Microsoft, Intel, dan lain sebagainya untuk melakukan berbagai pelatihan untuk para pengurus PGRI dan para guru anggota PGRI. Sedangkan di luar negeri, PGRI telah bekerja sama dengan organisasi guru di seluruh negara-negara ASEAN, Korea Selatan, Turki, dan China. Selain itu, PGRI juga bekerja sama Education International selama lebih kurang 20 tahun untuk melakukan pelatihan penguatan PGRI dan pengembangan kapasitas pengurusnya.

Education International adalah organisasi guru dunia dengan anggota lebih kurang 180 negara yang tergabung di dalamya. Pada tahun 2014, PGRI bersama Education International wilayah Asia Pacific dibantu oleh 5 negara donor (Swedia, Norwegia, 
Jepang, Amerika, dan Australia sebagai Consortium Partners) bersepakat untuk membuat pelatihan untuk mengembangkan dan menguatkan kapasitas dan kinerja pengurus PGRI di tingkat kabupaten/kota. 5 (lima) aspek yang menjadi tolok ukur dari meningkatnya kinerja pengurus PGRI yaitu 1) Peningkatan kapasitas pengurus, 2) Pengelolaan keanggotaan dan Peningkatan jumlah anggota, 3) Pengelolaan keuangan, 4) Gender Equality, dan 5) Kegiatan eksternal yang dilakukan sesuai dengan kebutuhan/program kerja.

\section{METODE}

Penelitian ini menggunakan pendekatan kualitatif karena penelitian ini bertujuan untuk mendeskripsikan pengaruh dari pendidikan dan pelatihan terhadap kinerja pengurus PGRI tingkat kabupaten/kota. Data penelitian ini berupa hasil evaluasi terhadap 5 aspek organisasi yaitu 1) peningkatan kapasitas pengurus, 2) pengelolaan keanggotaan dan peningkatan jumlah anggota, 3) pengelolaan keuangan, 4) keterlibatan perempuan dalam organisasi, dan 5) kegiatan yang sudah dilakukan berdasarkan kebutuhan yang telah dituangkan dalam pemetaan kebutuhan kabupaten/kota.

Sumber data dari penelitian ini adalah Pengurus PGRI Kabupaten Parigi Moutong, Provinsi Sulawesi Tengah dan Kabupaten Gunung Kidul, Daerah Istimewa Yogyakarta. Sebelumnya pengurus PGRI di kedua kabupaten tersebut kurang memahami prinsip dasar organisasi, perkembangan organisasi yang sangat lambat dan tidak responsive terhadap perubahan dan perkembanan zaman. Dalam penelitian kualitatif, ada beberapa teknik pengumpulan data yang digunakan. Sugiyono menyatakan ada empat macam teknik pengumpulan data dalam penelitian kualitatif yaitu observasi wawancara, dokumentasi, gabungan/triangulasi. [10] Teknik yang digunakan dalam penelitian ini adalah dokumentasi yaitu laporan perkembangan yang disampaikan oleh Pengurus PGRI Kabupaten Parigi Moutong dan Kabupaten Gunung Kidul setelah diadakannya pelatihan. Laporan disampaikan sebanyak 2 kali yaitu pada pertengahan tahun dan akhir tahun 2015.

Menurut Sugiyono kredibilitas hasil penelitian kualitatif ini akan semakin tinggi jika melibatkan / menggunakan studi dokumen ini dalam metode penelitian kualitatifnya hal senada diungkapkan Bogdan (seperti dikutip Sugiyono) " in most tradition of qualitative research, the phrase personal document is used broadly lo refer to any first person narrative produce by an individual which describes his or her own actions, experience, and beliefs".

Untuk prosedur analisis data menggunakan analisis deskriptif-kualitatif yaitu menginterpretasikan data yang telah terkumpul, seperti yang dinyatakan oleh Moh. Nazir, Ph. D yaitu analisis deskriptifkualitatif merupakan suatu teknik yang menggabarkan dan menginterpretasikan arti data-data yang telah terkumpul dengan memberikan perhatian dan merekam sebanyak mungkin aspek situasi yang diteliti pada saat itu, sehingga memperoleh gambaran secara umum dan menyeluruh tentang keadaan sebenarnya [11].

Data dianalisa menggunakan tabel hasil laporan perkembangan pada mid term evaluation meeting dan evaluation and planning meeting pada akhir semester dan memperoleh keabsahan laporan dari Sistem Informasi Keanggotaan (SIK) PGRI dan Aplikasi Sistem Informasi Keuangan (ASIK) yang terintegrasi di kantor Pengurus Besar PGRI dan wawancara beberapa pengurus dan anggota di wilayah masing-masing sehingga 
memudahkan untuk melakukan interpretasi dan membuat simpulan.

\section{HASIL DAN PEMBAHASAN}

Berdasarkan analisis data dapat ditemukan peningkatan kinerja pengurus di
Kabupaten Parigi Moutong dan Kabupaten Gunung Kidul setelah dilakukan pendidikan dan pelatihan di dua kabupaten tersebut seperti tabel di bawah ini [12]:

Tabel 1. Laporan Perkembangan Kinerja Pengurus dari Aspek Kapasitas Pengurus dan Keanggotaan (Mid Term Semester)

\begin{tabular}{|c|c|c|c|c|}
\hline \multirow{3}{*}{ District } & \multicolumn{4}{|c|}{ ASPECTS } \\
\hline & \multicolumn{2}{|c|}{ Board Member Capacity } & \multicolumn{2}{|c|}{ Memberhip Registration Data } \\
\hline & \multicolumn{2}{|c|}{$1 \quad 2$} & 1 & 2 \\
\hline Gunung Kidul, DIY & Low & Increased & 9.947 & 10.114 \\
\hline 4-9 Nov 2014 di Cyka & Motivation & motivation and & & (increase 167) \\
\hline Raya Hotel, Wonosari, & and Spirit & spirit of Board & & This data is excluded the \\
\hline Gunung Kidul & $\begin{array}{l}\text { from the } \\
\text { Board }\end{array}$ & member & & $\begin{array}{l}\text { offline data that the } \\
\text { members still being }\end{array}$ \\
\hline & Member & & & $\begin{array}{l}\text { recruited form } 18 \\
\text { branches in Gunung } \\
\text { Kidul. }\end{array}$ \\
\hline Parigi Moutong & PGRI Board & The capacity of & The number & The number of members \\
\hline District, Sulawesi & Member still & board member in & of members & registered in PB PGRI \\
\hline Tengah & has conventi- & district, branches is & registered in & database is 3246 (data \\
\hline 11-16 Nov 2014 di & onal way of & increased in & the data & March 2015) \\
\hline Grand Mitra Hotel & thinking, yet & leadership, & base of $P B$ & \\
\hline & can & managerial, and & PGRI was & \\
\hline & accommodate & membership system. & only 4 & \\
\hline & the maximum & & people. & \\
\hline & $\begin{array}{l}\text { potential of } \\
\text { members. }\end{array}$ & & & \\
\hline
\end{tabular}

Tabel 2. Laporan Perkembangan Kinerja Pengurus dari Aspek Pengelolaan Keuangan, Partisipasi Perempuan, dan Kegiatan Eksternal (Mid Term Semester)

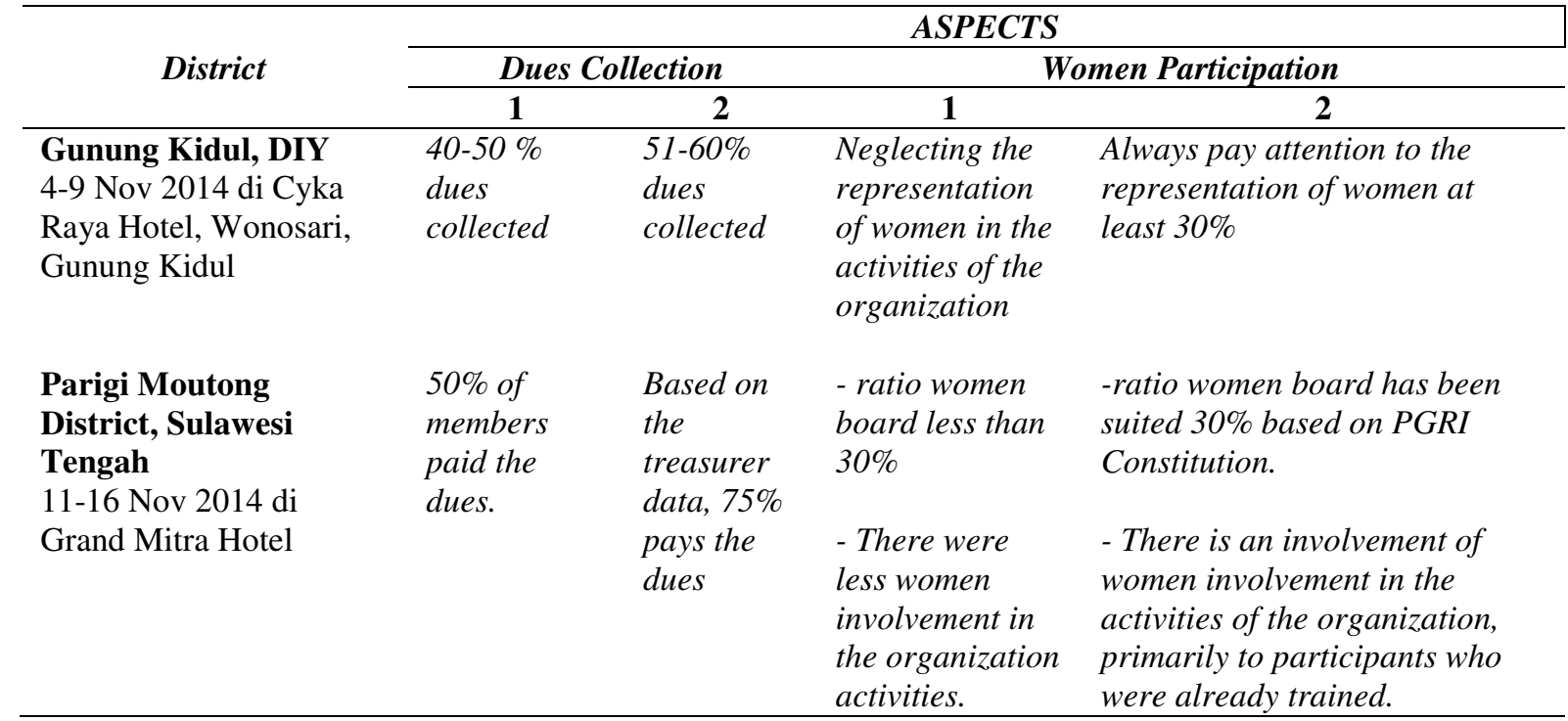


Tabel 3. Laporan Perkembangan Kinerja Pengurus dari Aspek Kegiatan Eksternal (Mid Term Semester)

\begin{tabular}{|c|c|c|}
\hline \multirow[t]{2}{*}{ District } & \multicolumn{2}{|c|}{ External activities implementation based on mapping } \\
\hline & 1 & 2 \\
\hline $\begin{array}{l}\text { Gunung } \\
\text { Kidul }\end{array}$ & $\begin{array}{l}\text { Calculation Simulation of } \\
P K G \text { and } P K B \text { and } \\
\text { Implementation of Curriculum } \\
2013 .\end{array}$ & $\begin{array}{l}\text { Simulation of PKG and PKB was implemented for KKG } \\
\text { (Teacher Certification Consortium) in Education } \\
\text { Department (Dinas Pendidikan) of Gunung Kidul in } 2015 . \\
\text { But it is needed to expand this activity in } 2016 . \\
\text { The solustion is PGRI made Cooperation with Disdik } \\
\text { include the activity in the Dinas' List of Budget } \\
\text { Implementation (DIPA) }\end{array}$ \\
\hline $\begin{array}{l}\text { Parigi } \\
\text { Moutong }\end{array}$ & $\begin{array}{l}\text { The Credit Score Assessment } \\
\text { Team of teachers'functional } \\
\text { position, in districts was not } \\
\text { established yet. }\end{array}$ & $\begin{array}{l}\text { There is the technical guidance meeting for the candidate } \\
\text { of Credit Score Assessment Team of teachers'functional } \\
\text { position. The resource person invited was from Ministry } \\
\text { of Education and Culture. }\end{array}$ \\
\hline
\end{tabular}

Tabel 1, 2, dan 3 di atas menyatakan bahwa dari aspek kapasitas pengurus di Kabupaten Gunung Kidul sebelum diadakan pelatihan (nomor 1) mereka memiliki motivasi yang lemah, jarang mengikuti rapat dan tidak banyak mengetahui tentang peraturan dasar organisasi. Setelah dilakukan pelatihan (nomor 2), motivasi kerja pengurus meningkat dengan cukupnya infrmasi tentang organiasi PGRI dalam pelatihan. Selain itu, dari aspek keanggotaan misalnya, di Parigi Moutong, sebelum pelatihan, hanya memiliki 4 anggota dalam data anggota di database PGRI. Namun, setelah diadakan pelatihan, jumlah anggota PGRI di Kabupaten Parigi moutong menjadi 3.246 dan pada akhir tahun 2015 (akhir semester) meningkat kembali menjadi 3.352 seperti yang diringkas dalam tabel 4 di bawah ini:

\section{Tabel 4. Ringkasan Kenaikan Jumlah Anggota di Gunung Kidul dan Parigi Moutong}

\begin{tabular}{cccc}
\hline District & $\begin{array}{c}\text { Before } \\
\text { Training }\end{array}$ & \multicolumn{2}{c}{ After Training } \\
\cline { 3 - 4 } & & $\begin{array}{c}\text { Mid } \\
\text { Term } \\
\text { report }\end{array}$ & $\begin{array}{c}\text { Evaluation } \\
\text { report }(\text { end of } \\
\text { year }\end{array}$ \\
\hline Gunung & 9.947 & 10.114 & 13.255 \\
$\begin{array}{c}\text { Kidul } \\
\text { Parigi }\end{array}$ & 4 & 3.246 & 3.352 \\
Moutong & & & \\
\hline
\end{tabular}

\section{Tabel 5. Laporan Perkemangan Kinerja Pengurus pada Aspek Pengelolaan Keanggotaan dan Pengelolaan Keuangan pada Akhir Semester}

A. Financial Management

\begin{tabular}{|c|c|c|c|}
\hline No & Output & Outcome & Recomendation \\
\hline 1. & $\begin{array}{l}\text { Parigi Moutong and Gunung Kidul } \\
\text { Districts have already implemented a } \\
\text { dues collecting through a check off } \\
\text { system and have agreement with } \\
\text { government }\end{array}$ & $\begin{array}{l}100 \% \text { members in Parigi } \\
\text { Moutong and Gunung } \\
\text { Kidul paid dues }\end{array}$ & $\begin{array}{l}\text { a. In 2016, all piloting districts } \\
\text { collect dues through a check } \\
\text { off system. } \\
\text { b. In 2017, all provincial } \\
\text { boards collect dues through a } \\
\text { check off system. }\end{array}$ \\
\hline 2. & $\begin{array}{l}\text { a. Finance administrators of Parigi } \\
\text { Moutong and Gunung Kidul have } \\
\text { been trained on training on PGRI } \\
\text { application of financial information } \\
\text { system (ASIK) } \\
\text { b. Participats agreement to use PGRI } \\
\text { application of financial information } \\
\text { system (ASIK) in managing finance }\end{array}$ & $\begin{array}{l}\text { a. Skilled treasurers and } \\
\text { finance administrators } \\
\text { in operating ASIK } \\
\text { PGRI } \\
\text { b. A total of members } \\
\text { who pay dues increase. }\end{array}$ & $\begin{array}{l}\text { a. Increasing a performance of } \\
\text { ASIK PGRI } \\
\text { b. In 2016, PGRI Procincial } \\
\text { Board using ASIK in } \\
\text { managing finance }\end{array}$ \\
\hline
\end{tabular}


B. Membership Consolidation

\begin{tabular}{|c|c|c|}
\hline No & Outcome & Recomendation \\
\hline 1. & $\begin{array}{l}\text { Secretaries of organisation and a. Data of PGRI } \\
\text { caderitation of Parigi Moutong } \\
\text { and Gunung Kidul board and } \\
\text { members } \\
\text { membership administrators in b. A real time of } \\
\text { have been trained. } \\
\begin{array}{l}\text { data } \\
\text { information. }\end{array}\end{array}$ & $\begin{array}{l}\text { a. Conducting replication on SIK } \\
\text { training for all secretaries of } \\
\text { organisation and caderitation of } \\
\text { district board and membership } \\
\text { administrator } \\
\text { b. Increasing the commitment of district } \\
\text { board to increase a total of members. }\end{array}$ \\
\hline 2 & $\begin{array}{l}\text { a. Desemination of the members } \\
\text { registration through online } \\
\text { b. PGRI Members registered in } \\
\text { the data base to increase, for } \\
\text { example in Gunung Kidul } \\
\text { become } 13.255 \text { and Parigi } \\
\text { Moutong become } 3.352\end{array}$ & $\begin{array}{l}\text { Presserizing provincial and district } \\
\text { board to recruit all teachers }\end{array}$ \\
\hline
\end{tabular}

Selain itu, para peserta juga terlatih menggunakan Sistem Informasi Keanggotaan (SIK) PGRI, bagaimana melakukan registrasi secara online, bahkan via handphone sekalipun bisa melakukan registrasi. Dari aspek pengelolaan keuangan, peserta juga terlatih melakukan pendataan dan pengelolaan menggunakan Aplikasi Sistem Informasi Keuangan (ASIK) PGRI yang lebih akuntabel dan transparan. Pengurus PGRI di Kabupaten Parigi Moutong dan Kabupaten Gunung Kidul berhasil melakukan lobby kepada pemangku kebijakan di wilayah masingmasing untuk melakukan check off system. Hasil lainnya adalah partisipasi pengurus perempuan dalam kegiatan organisasi meningkat. Tabel 5 [13] menjelaskan bahwa di akhir tahun/akhir semester $80 \%$ guru-guru yang ada di Parigi Moutong dan Gunung Kidul telah menjadi anggota PGRI dan $100 \%$ dari anggota tersebut telah membayar iuran. Hasil ini menunjukkan bahwa kinerja pengurus PGRI di dua kabupaten tersebut meningkat. Ini disebabkan pengurus PGRI yang telah mengikuti pendidikan dan pelatihan lebih memahami tugas dan tanggungjawab serta lebih termotivasi untuk meningkatkan kapasitas dirinya untuk ikut serta dalam menjadikan PGRI sebagai organisasi Kuat, Independen Demokratis, dan Sustainable untuk mencapai visi, misi organisasi.

\section{SIMPULAN}

Dari hasil penelitian dan pembahasan di atas, dapat disimpulkan bahwa pendidikan dan pelatihan yang sesuai dengan kebutuhan organisasi memberikan pengaruh terhadap peningkatan kinerja pengurus PGRI. Peningkatan kinerja pengurus PGRI sangat berpengaruh pada tercapainya visi, misi, dan tujuan organisasi baik jangka pendek (dalam bentuk program tahunan) maupun jangka panjang. 5 (lima) aspek yang menjadi tolok ukur dari meningkatnya kinerja pengurus PGRI yaitu 1) Peningkatan kapasitas pengurus, 2) Peningkatan jumlah anggota, 3) Pengelolaan keuangan yang baik, 4) Gender Equality, dan 5) Kegiatan eksternal yang dilakukan sesuai dengan kebutuhan/program kerja.

Pelatihan menjadi salah satu cara penting bagi PGRI untuk meningkatkan kapasitas dan kinerja pengurusnya. Kinerja dan kapasitas Pengurus PGRI Kabupaten Parigi Moutong dan Kabupaten Gunung Kidul meningkat setelah dilakukan kegiatan pendidikan dan pelatihan. Dalam penelitian ini juga ditemukan peningkatan kinerja pengurus di tingkat cabang-cabang yang berada di Kabupaten Parigi Moutong dan Gunung Kidul. Hal ini disebabkan pengaruh kinerja dan motivasi pengurus kabupaten di atasnya. Untuk penelitian lanjutan dapat disarankan agar dilakukan 
penelitian dengan mengambil objek lain berupa media pembelajaran dalam pendidikan dan pelatihan dengan subjek lain yang tidak banyak.

Bagi organisasi atau perusahaan, melakukan pelatihan secara berkelanjutan dengan topik sesuai kebutuan untuk pegawai/pengurus sangat berpengaruh pada kinerja mereka. Bagi Pengurus PGRI Kabupaten/Kota yang telah mendapatkan pelatihan, disarankan untuk melakukan replikasi pelatihan serupa untuk tingkat di bawahnya. Apabila ada kendala biaya, bisa dilakukan dengan cara kerja sama dengan dinas atau pihak-pihak terkait.

\section{DAFTAR PUSTAKA}

[1] Sutrisno Edy, Prof. Dr. H., Manajemen Sumber Daya Manusia. Jakarta: Prenadamedia Group, 2016.

[2] Tim Pengembang Ilmu Pendidikan FIP-UPI.. Ilmu dan Aplikasi Penddidikan. Bandung. PT. Imprial Bhakti Utama, 2007.

[3] Irawan, Andri, Pentingnya Pelatihan dalam Persoalan Kinerja SDM, vol. 10 No. 2, 2013.

[4] Dharta, I ketut. Pengaruh Pendidikan dan Pelatihan (diklat) terhadap Kinerja Pegawai Negeri Sipil Pada Sekretariat Daerah Kota Malang. Jurnal Ekonomi MODERNISASI. Volume 6, Nomor 2, Juni 2010. https://media.neliti.com/media/public ations/77515-ID-pengaruhpendidikan-dan-pelatihan-diklat.pdf (diakses pada 20 Maret 2018).

[5] Peraturan Pemerintah (PP) Nomor 31 Tahun 2016 tentang Sistem Pelatihan Kerja Nasional .
[6] Muchlisin Riadi, Pendidikan dan Pelatihan. http://www.kajianpustaka.com/2012/ 11/pendidikan-dan-pelatihan.html/.

[7] Maarif, M Syamsul dan Lindawati Kartika. MANAJEMEN PELATIHAN Upaya Mewujudkan Kinerja Unggul dan Pemahaman Employee-Engagement. Bogor: PT Penerbit IPB Press, 2014.

[8] Lubis, Khairul Akhir. Pengaruh Pelatihan dan Motivasi Kerja Terhadap Kinerja Karyawan PT. Perkebunan Nusantara IV (Persero) Medan (Tesis). Sekolah Pasca Sarjana Universitas Sumatera Utara. 2008.

[9] Basri, Hasan dan Rusdiana, Manajemen Pendidikan dan Pelatihan. Bandung: CV. Pustaka Setia. 2015.

[10] Sugiyono, Metode Penelitian kuantitatife, Kualitatife, dan R \& D. Bandung: ALFABETA. 2008.

[11] https://scholar.google.co.id/scholar?h l=id\&as_sdt=0\%2C5\&q=teknik+pen gumpulan+data+kualitatif\&oq=tekni k+pengum (diakses pada 22 Maret 2018).

[12] Audit Report of Mid-Term Evaluation Program Cooperation PGRI-Education Inernational Consortium Project Year 2015 (June 2015).

[13] Report on The Implementation of Program Cooperation PGRIEducation Inernational Consortium Project Year 2015 (Evaluation and Planning Meeting on December 2015 